\title{
Prediction of Depression through Early Maladaptive Schemas
}

\author{
Mahdie Fouladi \\ Department of Psychology, University of Mysore, Mysore, India \\ Email Address: mahdie.fouladi@gmail.com Tel: 00989301084322
}

\section{Doi:10.5901/mjss.2015.v6n1s1p602}

\begin{abstract}
The aim of the present project was assessing the correlation between Young's early maladaptive schemas model and depression symptoms between non-hospitalized depressed patients and healthy group. Early maladaptive schemas (EMSs) are stable and trait-like underlying beliefs that considered as the infrastructure of recurrent and chronic psychological disorders. In this study, the correlation between these schemas and chronic depression disorders are evaluated. In this project, 47 nonhospitalized depressed patients who referred to the health care and clinical centers of Kermanshah city, during a year, were detected by using structured interview and Beck Depression Inventory (BDI-II). Also, 49 cases referred to clinics for mild problems were considered as the control group (=N96). Fifteen EMSs were measured through Young Schemas QuestionnaireShort Form Schemas (YSQ-SF). The data was analyzed using correlation and multiple regression method. The highest meaningful correlation was ascribed to the schemas of disease and vulnerability to harm (r=0.64) and the lowest one was achieved by schemas of constraints hampered $(r=0.45)$. By using stepwise multiple regression model, with combination of four schemas of disease and vulnerability to harm, social isolation, emotional inhibition, and continence/insufficient discipline about $61 \%$ ( $r 2=0.61)$ of chronic depression changes could be explained. The four schemas of EMS, vulnerability, social isolation, emotional inhibition, and continence/insufficient discipline enable to present the largest amount of variance of the dependent variable or so called chronic depression. However, schemas like failure to achieve, abandonment, mistrust, emotional deprivation, defectiveness / shame, dependency, subjugation, self-sacrifice, unrelenting standards, entitlement, and self-control cannot significantly predict the major parts of dependent variables. The findings showed that EMSs have a positive correlation with the severity of depression' and chronic depression can be predicted with a high accuracy through these schemas. The accuracy of this prediction in the rejection cut is higher than other fields.
\end{abstract}

Keywords: Early maladaptive schemas, chronic depression, cognitive theory of depression, schemas fields.

\section{Introduction}

A significant progress in cognitive theory and cognitive therapy fields of depression disorder has been achieved during the third past decades. Although theorists have challenged regarding the adjustment and review of cognitive therapy, all different theories have a mutual frame based on which they stressed on the role of maladaptive schemas in initiate and duration depression (1). Mood disorders are a common group of clinical disorders in which the sense of mastery is gone and the person takes enormous suffering. In the newest studies, major depression disorders have the highest prevalence of longevity among psychiatric disorders (about 17\%) (2). The depression clinical disorder includes major depression and dysthymic (chronic depression). Major depression is a kind of disorder detected with one or more periods of major depression. The characteristics of depression periods are the symptoms which may include depressed mood, loss of interest or pleasure in activities, dysfunction, changes in appetite or sleeping habits, feelings of guilt and worthlessness, and lack of focus (3). When the criteria of those two years exist, it is called chronic depression (2). Martin Seligman in 1975 named the major depression as "cold" in psychiatry (4). Today the depression status has exacerbated after last three decades and about 121 millions of people are affected globally (5); in fact, the rate of depression symptoms has increased among all age groups and societies (6). According to World Health Organization (WHO) research, depression is one of the major reasons of disability (5). Also, based on the findings of $\mathrm{WHO}$, it is predicted that depression will be imposed the second major burden on the global health in 2020 (7). Nejati safa quoted from the big epidemiology of Nourbala et al., who studied on 35014 people, declared the rate of depression prevalence $21 \%$ in Iran (8). Considering the concerning statistics of psychiatric disorders prevalence, especially depression disorder, in this country the importance of recognizing and treating this disorder is clear. One of the causal theories of depression disorder is cognitive theory of depression (9). This theory states that depression symptoms are the result of maladaptive recognitions which mediate the relationship between conditions and responses (these responses may emotional, physiological, or behavioral). Thus, depression does not happen based on one condition and arises from perceptions and underlying 
beliefs of the person regarding that condition. The cognitive theory also detects the underlying determinants which may be responsible for creating and keeping depression, including automatic negative thoughts, attribute on biases, and schemas. In cognitive theory, high volume of investigations studied the relationship between automatic thoughts and depression. Automatic thoughts involve the fast, evaluative, and surface recognitions that are briefly presented and are often unconscious. According to Beck, automatic thoughts are reflexive and typically seem real without asking about their logic (10). In depressed people's automatic thoughts are persistently negative and increasingly significant (11). Schemas are the absolute fundamental truths which separate the perceptions of individuals from their experiences. These underlying beliefs exist in all people and present a frame to percepting the world. The schemas provide the possibility of more effective evaluation from experiences, which may happen out of the conscious awareness of the person (9). The main concept of the cognitive theory is that depressive schemas are the stable cognitive structures which get inactive during symptoms improvement (12). These inactive cognitive structures get active as a result of stressful life events and also facilitate the access to the complicated network of saved personal information. These personal data are often undesirable and stimulate the depression (9). The schemas are activated when people expect stimulations to invade them, in other words hurt them. The results of several studies have supported this idea and shown that the combination of schemas and psychiatric pressure can be more related to negative emotions $(13,14,15)$. The more practically model of schemas, is Young's early maladaptive schemas model (16). According to Young's view it was revealed that some people have a rigid character structure and don't satisfactorily respond to the traditional cognitive-behavioral therapy for Axis I disorders. The clinical experiences of Yang conducted him to formulation of the conceptual model of EMSs. This model detected patterns of cognitive disposition, which are counted as the infrastructure of Axis I and II disorders, and stressed mainly on the initial growth factors with current dysfunctional thoughts. Consistent with Beck schemas idea, this model states that EMSs are often activated as a response to hostile environment, in a situation compatible with individual's functioning and self-concept. An adaptive thinking can be incompatible when the person is not in the situation and may begin to become permanent in contrasting positions which is familiar for the subject. For consisting the beliefs and confirming their schemas' context, Individuals change the information related to themselves, universe, and their experiences in a way that lead to misunderstanding and generalized extreme. Yang et al. have shown that EMSs which are grown and become strength in the early growth ages, are those which have been arisen from inefficient familiar experiences (16). Eighteen Young's EMS model were categorized in five extend areas. The first area was the rejection cut concludes fundamental beliefs of the person about need for acceptance and love which is not met. Autonomy and impaired performance, as the second area, is created as the result of excessive parental support or vice versa, too much neglect of them, which causes that the person has failed in growing the autonomy and independent character. People who have schemas of the third area (restrictions hampered) tend to lack discipline and respect for others. The fourth area (other Favorites) includes forbearing of one's own needs and preference others' requirements; in extreme cases, it could be lead to lack of awareness from desires and emotions of one's own. The fifth and last area is hypervigilance and preventing involves rigid beliefs of people about themselves, others, and the world that lead to vigilance, prevention, and stay away from the world (16). EMSs are persistent during the time with persons who confirm the same schemas, especially those belong to the rejection cut, and don't be destroyed $(1,17,18)$. EMSs also have correlation with depression period, history of period depression, and dangerous factors for depression, include prevention and poor selfdirected (19). Also, EMSs have relationship with dysfunctional attitudes, overall negative affection, and poor esteem (1, $20,21)$. When depression is measured by Beck Depression Inventory-II (BDI-II), all the five areas present a significant percentage of depression (22). In addition when researchers statistically controlled the current symptoms of depression, negative affection, and character disorders, EMSs showed higher correlation with chronic depression $(1,20)$. Schmidt et al. were the first group evaluated the questionnaire factors of Young's EMSs (20). Researchers has firstly performed the factor analysis of main questionnaire and explored its structure factor. The results of factor analysis supported three higher orders which were named as cut, extreme need to communicate, and exaggerated criteria. EMSs of cut factor had tend to feelings of alienation and emotional inhibition, while extreme need to communicate correlated with the trapped and extreme need to others; both of these two groups are in a danger of depression. The third high level factor (exaggerated criteria) involves the extreme concentration on personal progress or in other side self-denial and excessive feelings of guilt. In one of sample students and also one of clinical cases, 15 factors of 16 were extracted and only the adverse social factor remained. EMSs have shown a high correlation with general distress, negative affection, and depression as well as anxiety symptoms whereas revealed a negative association with self-esteem. Although the concept of EMSs has provided a valuable extension for cognitive theory of depression, concept of automatic thoughts, and dysfunctional attitudes, there are a few studies regarding the correlation between EMSs and depression symptoms. Calvete et al. in a non-hospitalized depressed case showed that schemas of failure to achieve, defectiveness / shame, and self-sacrifice have relationship with depression symptoms (23). Another study of Harris and Curtin revealed that 
EMSs of defectiveness / shame, insufficient self-control, vulnerability, and incompetence / inferiority in undergraduate students correlate to the severity of depression symptoms (24). In a clinical research done by Young and Brown on patients with more depression, it was detected that the total score of Young and Brown's EMSs questionnaire had a correlation with the severity of depression symptoms, even after controlling the neurotic and other personality traits (25). It was declared that EMSs show the higher variance in depression severity than structures like this character which is detected as dependent to depression symptom such as Neuroticism (26). In another clinical case with depression symptoms, Petrocelli et al. revealed that schemas of abandonment / instability, defectiveness / shame, failure to achieve, compliance, and vulnerability to injury have a cross-sectional relationship with depression severity (27). Halvorsen et al. showed that in areas of undesirability, autonomy, and disturbed function schemas of depressed patient's the hampered restrictions have a cross-sectional relation with depression severity (28). Also, Shah and Waller study stated that in nonhospitalized depressed patients EMSs of defectiveness / shame, self-sacrifice, and inadequate self-sufficiency have association with the severity of depression symptoms (29). A combined-research regarding to the schemas areas and EMSs specified for depression severe symptoms displayed that an extend range of EMSs, especially those belong to self-determination, disturbed function, and rejection cut, have a correlation with depression severe symptoms. While the previous researches were exclusively focused on the simultaneous relationship between EMSs and depression symptoms, the correlation of EMSs with improving symptoms in the period of depression therapy remained unclear. When the study on the correlation between EMSs and depression symptoms was performed in depressed patients, determining the remain of EMSs during changing signs (like treatment period) had importance. One of the basic premises in the theory of schemas therapy is that EMSs are durable and structures like features, resistant to change. Therefore, no one is waiting for changing EMSs in a short period of treatment, which more focuses on reducing the depression signs instead of decreasing the EMSs (1). Long-term sustainability of EMSs in 55 non-hospitalized depressed patients had been evaluated in a period of 2.5-5 years and found that EMSs show good durability like what is seen in the character disorder (1). In addition, Wang et al. found an average durability of most EMSs in depressed patients after nine years following (21). Although these studies have shown a good durability of EMSs in such patients, the stability of EMSs during the non-hospitalized treatment period for depression remained unclear. In Colman, Gorden, and Mackfi study from Tennessee University the correlation between EMSs and depression was assessed (30). These researchers in this study evaluated the validity of EMSs areas in explaining the depression severity among students ( $\mathrm{N}=82)$, after controlling sex, cognitive vulnerability, rumination, experiential avoidance, social problem-solving ability, and anxiety. In terms of BDI-II, the depression was reported based on self-assessment scale of 0-47 among students (from no depression to severe depression) (31). The reported depression severity was significantly predicted based on hierarchical regression analysis, sex, rumination, the first area of EMSs (rejection and cut) and the second one (autonomy and impaired performance) and the greatest amount of variance presented. The previous analysis have declared that abandonment $I$ instability, social isolation / alienation, defectiveness / shame (the first area) and failure to achieve, dependence / incompetence, and vulnerability to harm (the second area) were achieved the most prediction of depression severity. The results strongly supported the concurrent validity of EMSs for explaining the increasing variance in prediction of depression severity (area I: 7\%, II: 8\%, combined I and II: 10\%). In Renner et al. research the correlation of EMSs, depression severity, and stability of EMSs during the period of depression therapy was studied in the natural condition of treating non-hospitalized patients (32). The sample study includes 132 non-hospitalized patients underwent treatment due to mood disorders in Netherlands. The participants had completed the scales of depression and EMSs 16 weeks before beginning the therapy. The findings showed that especial EMSs (failure to achieve, emotional deprivation, abandonment / instability) had relation with the severity of depression symptoms as cross- sectional. In addition, autonomy and impaired performance areas before treatment displayed a positive relationship with depression levels in 16 weeks of following therapy. On the other hand, inhibition and vigilance areas before treatment had a negative relation with evaluation during control of depression severity. The findings of this research revealed that some specific areas of schemas, resistant to treatment, can predict the outcome of therapy. In Harris and Curtin study, entitled evaluation of EMSs, perceived parenting and depression symptoms among young students $(\mathrm{N}=194)$ were determined, EMSs of defectiveness / shame, poor self-control, vulnerability showed correlation with loss or illness, incompetence / inferiority of perceived parenting and depressive symptoms (33). The project of Asfarjani, Dolatshahi, Mohammad khani, and Pourshahbazi on 116 samples included 58 depressed patients and 58 healthy cases without the history of depression by using EMSs questionnaire and BDI-II showed that in all EMSs there was a significant difference between depressed and non-depressed individuals; also, in patients with major depression schemas of social isolation, subordination, and failure to achieve were seen. Moreover, this study declared that in physical, vegetable, pessimism and worthlessness signs the schemas of social isolation and in psychological signs schemas of dependence / incompetence were taken as the most important active schemas. Anmuth project results regarding to the role of EMSs in prediction of depression and anxiety 
presented that EMSs enable to predict these disorders but the negative experiences have more effect. Furthermore, the role of EMSs was more in anxiety signs' prediction into depression signs. Additionally, depression might show less correlation with little progress than interpersonal negative events (34).

\subsection{Research hypothesis}

The Main hypothesis: based on EMSs can predict depression symptoms.

The first specific hypothesis: There are an association between EMSs and the chronic depression symptoms.

The second specific hypothesis: There are an association between different areas of schemas and the chronic depression symptoms.

\section{Material and Method}

The present study is a kind of correlation study that variables were measured through standard questionnaires and the association among variables have been calculated by using correlation and regression statistical methods.

\subsection{Population and sample}

The statistical population of present study included all patients with chronic depression referred to clinics, psychiatric hospitals, psychology, and consulting clinics of Kermanshah city through October 2012 to September 2013. Samples of present study were chosen from patients referred to treatment centers and consulting clinics of Kermanshah city. Frothy seven patients out of 380 non-hospitalized chronic depressed patients referred to these centers during October 2012 to September 2013 and 49 non-depressed patients who had not been observed with any clinically distinct disorders were selected randomly from five treatment centers as control group. To choose patients in addition to Structured Clinical Interview for DSM-IV Axis I Disorders (SCID-I) performed by a clinical psychologist or psychiatrist, the Beck depression inventory second edition (BDI-II) questionnaires were used too. Of these, $56.25 \%$ were female and $43.75 \%$ male. Participant's age range, mean, and median were from 20 to 40 years, 29.67, and 30, respectively.

\subsubsection{Scales}

\subsubsection{Structured Clinical Interview for DSM-IV Axis I Disorders (SCID-I)}

Selection of patients was performed based on their medical records at the clinic, treatment center or hospital. Afterwards, the individual in SCID-I received a final diagnosis of depression or previous diagnosis was confirmed.

\subsubsection{Demographic questionnaire}

In this study to obtain participant's information the demographic questionnaire was used. This questionnaire consisted of several variables such as age, gender, marital status, disease onset, duration of suffering, etc.

\subsubsection{Depression Scale: Beck Depression Inventory-II (BDI-II)}

To measure the severity of depression in patients the BDI-II questionnaire [31] was used. This self-assessment scale has 21 items that the scoring would be 0 to 3 based on the severity of depression in recent two weeks. The score 0 indicates nothing and 3 indicates the highest intensity in that item. Participants may be obtain a total score from zero to 63 which 63 represents the highest rate of depression and zero represents the absence of any depressive moods [35]. Dosis and others [36] were used both the BDI [9] and BDI-II questionnaires [31] in a sample consisted of 511 factor analysis undergraduate students. A high internal consistency were observed in several studies (0.91), also, adequate diagnostic validity were seen in several investigations too [31, 37]. A significant difference were not seen between men and women [36]. Results of studies in cut-off points of questionnaire have supported non-depressed (0 to 12), boredom (13-19), and depress individuals (20-63). The second edition of BDI has more consistency with the DSM-IV. Items of this questionnaire cover all parameters of depression cognitive theory. The Results of the test-retest reliability study within a week was reported 0.94[38]. The internal stability for the Iranian students and test-retest reliability of this scale within a week have been reported 0.87 and 0.73 , respectively [38]. The Fati in a sample of 94 people in Iran has also reported 
0.91 Cronbach's alpha coefficient and 0.96 test-retest reliability of this scale in a week [39]. The Short form of YSQ is a self-assessment tool. Seventy five items of this questionnaire designed by Yang [25] for evaluating 15 EMSs. These schemas including emotional deprivation, abandonment / instability, mistrust / Abuse, social isolation / alienation, defectiveness / shame, failure to achieve, dependence / incompetence, vulnerability to harm or illness, enmeshment / undeveloped self, subjugation, self-sacrifice, emotional inhibition, unrelenting standards / hyper criticalness , entitlement / grandiosity, and insufficient self-control. Each item is scoring in 6 degrees. ("1" for completely false and "6" for completely correct). In all items high scores indicate that maladaptive schemas are more harmful. This scale in wide range of different populations have been validated in terms of clinical and psychometric [40, 41, and 42]. In Iran Ghiyasi has studied the validity of scale and showed it [43]. Ghiyasi (2008) has reported the alpha coefficient's of this scale $(a=0.94)$ and for their subscales has reported coefficients from 0.60 to 0.90 . Also, YSQ-S has shown the discriminant and convergent validity in comparison with the dysfunctional attitude scale. In jalili et al.'s study (2011) this amount was sufficient for this scale $(a=0.94)$.

\subsection{Method}

Non-hospitalized depressed patients completed questionnaires through the structured interview and Beck depression test after diagnosis. The control group were healthy subjects referred to the consulting clinic for minor problems and completed the questionnaires.

\section{Results}

Data analysis of questionnaires was performed by SPSS software. At first, due to the linearity of the relationship and normality of distribution, variables were tested and non-relevant data excluded from the study. Also, descriptive parameters including the average, standard deviation, and strain and tilted of distribution were calculated too (table 1). The reliability of scales were calculated before data analysis. The reliability coefficient of YSQ-SF subscales were obtained for the emotional deprivation schemas (0.85), abandonment (0.77), mistrust / abuse (0.82), social isolation (0.82), defectiveness / shame (0.85), failure to achieve $(0.87)$, dependence / incompetence $(0.80)$, vulnerability $(0.84)$, enmeshment (0.82), subjugation (0.80) self-sacrifice $(0.70)$, emotional inhibition $(0.80)$, unrelenting standards $(0.70)$, entitlement (0.73), and self-control ( 0.74$)$; and the total reliability of scale has been obtained by the Cronbach's alpha method ( $\alpha=0.94)$ and this coefficient is adequate and appropriate for the questionnaire. The lowest rate of alpha coefficient related to the self-sacrifice and unrelenting standards ( $\alpha=0.70)$, and the highest one to the failure to achieve $(a=0.87)$.

Table 1: Table of descriptive indicators for the EMSs in depressed and non-depressed

\begin{tabular}{|c|c|c|c|c|c|c|c|c|}
\hline \multirow{3}{*}{ EMSs } & \multicolumn{8}{|c|}{ Depression } \\
\hline & \multicolumn{4}{|c|}{ Depressed } & \multicolumn{4}{|c|}{ Non-Depressed } \\
\hline & mean & SD & Skewness & tilted & mean & SD & Skewness & tilted \\
\hline Emotional deprivation & 17.09 & 7.54 & -0.03 & -0.03 & 10.33 & 5.37 & 0.39 & 0.07 \\
\hline Abandonment & 15.47 & 5.82 & -0.07 & -0.11 & 13.92 & 5.85 & -0.08 & 0.53 \\
\hline mistrust & 15.66 & 6.65 & -0.71 & 0.00 & 11.43 & 5.06 & 0.14 & 0.92 \\
\hline Social isolation & 14.83 & 6.29 & -0.09 & 0.39 & 7.68 & 3.67 & 0.47 & 0.25 \\
\hline shame /defect defectiveness & 12.11 & 6.37 & 0.26 & 0.30 & 6.86 & 2.81 & 0.45 & 0.26 \\
\hline failure to achieve & 14.53 & 7.01 & -0.18 & 0.23 & 8.49 & 3.34 & 0.28 & 0.31 \\
\hline dependency & 18.49 & 6.22 & 0.14 & 0.04 & 18.45 & 9.04 & 0.26 & 0.38 \\
\hline vulnerability & 14.98 & 6.02 & 0.12 & 0.13 & 7.86 & 3.25 & -0.36 & 0.09 \\
\hline Self-undeveloped & 13.66 & 6.64 & 0.11 & 0.27 & 12.02 & 6.37 & -0.02 & 0.11 \\
\hline subjugation & 12.47 & 6.12 & -0.18 & 0.28 & 9.39 & 4.48 & -0.43 & 0.19 \\
\hline self-sacrifice & 19.09 & 5.02 & -0.08 & 0.29 & 16.84 & 4.90 & -0.33 & 0.40 \\
\hline Emotional inhibition & 16.32 & 5.45 & -0.72 & 0.12 & 10.02 & 5.29 & $0 / 18$ & 0.43 \\
\hline unrelenting standards & 19.00 & 5.15 & -0.06 & 0.41 & 17.06 & 6.03 & -0.43 & 0.06 \\
\hline merit & 16.42 & 5.78 & -0.24 & -0.09 & 13.82 & 4.57 & 0.35 & 0.31 \\
\hline self-control & 16.64 & 6.04 & -0.13 & -0.10 & 12.00 & 4.69 & -0.92 & 0.22 \\
\hline
\end{tabular}

To test the specific hypothesis of study the correlation of related variables were evaluated using the Pearson correlation 
coefficient model (Table 2).

Table 2: The correlation between EMSs and depression syndrome

\begin{tabular}{|l|c|c|c|}
\hline \multirow{2}{*}{ variables } & \multicolumn{3}{|c|}{ depression symptoms } \\
\cline { 2 - 4 } & $r$ & Sig. & r2 \\
\hline Emotional deprivation & $0.49^{\star *}$ & 0.001 & 0.24 \\
\hline Abandonment & 0.14 & 0.17 & 0.20 \\
\hline mistrust & $0.42^{\star \star}$ & 0.00 & 0.18 \\
\hline Social isolation & $0.51^{\star *}$ & 0.00 & 0.26 \\
\hline shame/ defectiveness & $0.48^{\star \star}$ & 0.00 & 0.23 \\
\hline failure to achieve & $0.45^{\star \star}$ & 0.00 & 0.11 \\
\hline dependency & 0.11 & 0.30 & 0.01 \\
\hline vulnerability & $0.59^{\star *}$ & 0.00 & 0.35 \\
\hline undeveloped self & 0.11 & 0.28 & 0.01 \\
\hline subjugation & $0.41^{\star \star}$ & 0.00 & 0.17 \\
\hline self-sacrifice & $0.30^{\star \star}$ & 0.003 & 0.09 \\
\hline Emotional inhibition & $0.52^{\star *}$ & 0.00 & 0.27 \\
\hline unrelenting standards & 0.14 & 0.17 & 0.20 \\
\hline merit & 0.13 & 0.22 & 0.02 \\
\hline self-control & $0.48^{\star \star}$ & 0.00 & 0.23 \\
\hline Total schemas & $0.68^{\star \star}$ & 0.00 & 0.46 \\
\hline
\end{tabular}

** Significant at the 0.01 level.

Considering to the achieved coefficients can be concluded that EMSs are vulnerable to the harm and illness, emotional deprivation schemas, mistrust, social isolation, defectiveness and shame, failure to achieve, subjugation, self-sacrifice, emotional inhibition, and self -undeveloped; and all schemas have positive and significant correlations with depression symptoms $(p<0.05)$; but the abandonment schemas, self -undeveloped, enmeshment, entitlement, shame, and unrelenting standards did not show any significant and positive correlation with depression symptoms. Therefore, there are sufficient evidence to confirm first specific hypothesis and it can be said that between the majority of EMSs and depression symptoms are a significant positive correlation. The column of squared correlation ( $\mathrm{r} 2$ ) is a kind of determination coefficient that represents the rate of depression through EMSs. The total coefficient of scale shows that $46 \%$ of the depression variance can be attributed through EMSs. To test the second specific hypothesis, the correlation between schemas areas and depression symptoms have been calculated using Pearson correlation coefficient (Table3). Calculated coefficients show that all areas of schemas have positive correlation with rate of depression at the level of 0.01 and of these the ejectment and rejection areas (0.64) had the highest amount of positive correlation with depression and the area of impaired limitations had the lowest $(0.446)$. It should be mentioned that all of these correlations are significant at least at alpha level 0.01 . Then it can be said that all areas of schemas have positive and significant correlation with depression symptoms. Hence, sufficient evidences have obtained to confirm the second specific hypothesis (significant at the 0.01 level.).

Table 3: The correlation between schemas areas and depression

\begin{tabular}{|l|c|c|c|}
\hline \multirow{2}{*}{ variables } & \multicolumn{3}{|c|}{ Dependent variable: chronic depression } \\
\cline { 2 - 4 } & correlation coefficient & Significant level & determination coefficient \\
\hline Rejection and ejectment & $0.64^{\star *}$ & 0.00 & 0.41 \\
\hline Autonomy and impaired performance & $0.469^{\star *}$ & 0.00 & 0.22 \\
\hline impaired limitations & $0.446^{\star *}$ & 0.00 & 0.20 \\
\hline direction & $0.454^{\star *}$ & 0.00 & 0.21 \\
\hline Vigilance/restrain & $0.47^{\star *}$ & 0.00 & 0.22 \\
\hline
\end{tabular}

** Significant at the 0.01 level.

\subsection{Multiple regression analysis}

The Main hypothesis: based on EMSs can predict depression symptoms. To test the main hypothesis of study, the 
regression equation have been calculated by stepwise method for independent variables or the very EMSs and independent variable in which that is the same depression (Table 4). As it can be seen in Table 4 the amount of obtained $\mathrm{r}^{2}(0.613)$ means that near 61 percent of the variance of chronic depression variable can be attributed to four schemas; vulnerability to the harm and illness, social isolation, emotional inhibition, and self-control. In other words, approximately 61 percent of distribution observed in chronic depression variable is explained by these schemas. The observed value of $\mathrm{R}(0.78)$ indicates that present model of linear regression can be used for prediction of chronic depression. Furthermore, the ratio of calculated $F(35.98)$ is significant at least at a confidence interval $99 \%$. Yet, referring to the t-statistic and significant levels can be judged that among 15 schemas, only four EMSs are significantly correlated with chronic depression and other variables although have significant correlation, because of cross-correlation don't have any significant specific effects on prediction of depression. However, the significance levels of these correlations are individually significant (Table 2). Findings of table 4 show that EMSs can predict depression significantly. Then, the second hypothesis is confirmed and the zero hypothesis rejected.

Table 4: Summary of regression analysis for prediction of depression symptoms trough EMSs

\begin{tabular}{|l|c|c|c|c|}
\hline Predictor & Standardized coefficients & Non-Standardized coefficients & $\mathrm{t}$ & Sig. \\
\hline Stable amount & & -12.91 & -4.55 & $0.000^{\text {** }}$ \\
\hline vulnerability & 0.417 & 0.93 & 5.99 & $0.000^{\star *}$ \\
\hline Social isolation & 0.26 & 0.56 & 3.44 & $0.001^{\text {** }}$ \\
\hline Emotional inhibition & 0.27 & 0.58 & 3.76 & $0.000^{\star *}$ \\
\hline self-control & 0.19 & 0.44 & 2.63 & $0.000^{\star *}$ \\
\hline Emotional deprivation & 0.18 & 0.33 & 1.69 & 0.93 \\
\hline dependency & -0.15 & -0.27 & -1.65 & 0.103 \\
\hline self-sacrifice & 0.12 & 0.31 & 1.50 & 0.137 \\
\hline Abandonment & -0.12 & -0.27 & -1.39 & 0.168 \\
\hline undeveloped self & 0.08 & 0.16 & 0.92 & 0.363 \\
\hline mistrust & 0.09 & 0.19 & 0.88 & 0.379 \\
\hline unrelenting standards & 0.06 & 0.14 & 0.64 & 0.525 \\
\hline merit & -0.05 & -0.12 & -0.45 & 0.652 \\
\hline failure to achieve & 0.05 & 0.10 & 0.36 & 0.718 \\
\hline defectiveness / shame & 0.05 & 0.11 & 0.36 & 0.712 \\
\hline subjugation & -0.05 & -0.12 & -0.36 & 0.721 \\
\hline
\end{tabular}

$\mathrm{R}=78.0 \quad \mathrm{R}^{2}=61.0 \quad$ Adjusted $\mathrm{R}^{2}=60.0 \quad \mathrm{~F}=35.98^{\star \star}$

** Significant at the 0.01 level.

\section{Discussion}

Depression cognitive theory states that EMSs may be responsible of certain perceptions and negative beliefs verification that can be led to depression and other mental disorders. Yang et al. developed the cognitive theory by stating that early maladaptive experiences make person to a growing beliefs that may be useful in period of time, but incompatible in variable conditions and result in cognitive complicated patterns [16].In Yang's model the cognitive vulnerability made operational by definition of 18 EMSs which have been organized in 5 areas. Investigations have shown the relationship between EMSs and communication problems, increasing stress, and risk of depression and anxiety. Theorists believe that EMSs will be active in long-term and have relationship with cognitive chronic damages or will be active with negative events that confirm the individual beliefs and caused to psychological damage. The result of first hypothesis showed a significant correlation between EMSs and depression which in line with results of Smith (20), Kalvit et al. [23], Harris and Kortin [24], Young and Brown [25], Petrosily et al. [27], Halorsen et al. [28], Coleman, Gordon, and Mokfi [30], Reiner et al. [32], Asfarjani et al.[44], emmos [34], Hankin, Abramson, Miller, and Hayfel 45].These correlations for various schemas are at an intermediate levels. This finding is similar with Abla et al. [46] and Eberhart et al. [47]. Findings of the second hypothesis showed that four EMSs; vulnerability, social isolation, emotional inhibition, self-control / insufficient selfdiscipline are unable to explain the largest amount of dependent variable variance or the same depression.

But schemas like failure to achieve, abandonment, mistrust, emotional deprivation, defectiveness / shame, dependence, subjugation, self-sacrifice, unrelenting standards, entitlements, and self-control cannot significantly predict substantial contribution of dependent variable. This finding is consistent with part of Coleman, Gorden, and Mokfi's 
studies [30]. In kolman et al. study based on the hierarchical regression and subsequent analysis revealed that abandonment / instability, social isolation / alienation, defectiveness / shame, and failure to achieve, dependence / incompetence, vulnerability to harm or illness had most prediction of depression intensity, while in present study four maladaptive schemas ; vulnerability, social isolation, emotional inhibition, self-control / insufficient self-discipline obtained the highest rate of explanation of depression[30]. In addition, results of the present study show that the mean of depressed individuals in total score of EMSs has significant difference with non-depressed individuals.

Additionally, the total score of individual in EMSs shows direct relationship with depression score. It means that the more scores in EMSs, the more scores in depression, but the rate of this correlation in comparison with previous studies was more [34],[20], and[48]. According to the findings of this study, the ejectment area (I) (schemas of instability, mistrust, abuse, emotional deprivation, defectiveness, shame, social isolation) shows the largest rate of correlation with depression. After this area, the area (II); the too much vigilance / restrain (too much restrain), the area (III); selfdetermination and impaired performance (schemas of dependence, incompetence, vulnerability to harm or illness, un self-developed, enmeshment, and failure to achieve), the direction area (IV) (Schemas of subjugation, self-sacrifice, and accepting/attention), the impaired limitations area (entitlements/ grandiosity, insufficient self-control / self-discipline,) have significant correlation with depression. this finding in line with most previous studies; Schmidt et al. [20], Kalvit et al. [23], Harris and Kortin [24], Young and Brown [25], Petrosly et al. [27], Halorsen et al. [28], Coleman, Gordon,and mokfi [30], Reiner et al. [32], Asfarjany et al. [44], enmos [34], Hakin, Abramson, Miller, and Hayfel [45]. Results of this research show that as much as person's schemas increase, more likely to develop depression and despite of EMSs can predict the probability of depression incidence in individual accurately. Whatever the rate of these schemas being more, the probability of recurrence or repetition of depression periods in patient's life increase more and since treatment of EMSs is time-consuming and long-term [32], short-time treatments will not lead to a definite cure of depression and the probability of recurrence or relapse would be exist .

One of the limitations of present study was using the YSQ-SF, because it can only assess 15 schemas or factors, but by using the long version of Yang's questionnaire can assess 18 EMSs.

\section{References}

[1]- Riso L.P., Maddux R.E., and Turini-Santorelli N.2007. Early Maladaptive Schemas in Chronic Depression. In L. Riso, P. duToit, D. Stein, \& J. Young (Eds.), Cognitive Schemas \& Core Beliefs in Psychological Problems: A Scientist Practitioner Guide. American Psychological Association. pp. 41-58.

[2]- Sadock BJ, Kaplan HI, Sadock VA. 2007,Kaplan \& Sadock's Synopsis of Psychiatry: Behavioral Sciences/clinical Psychiatry: Wolter Kluwer/Lippincott Williams \& Wilkins; pp 527-578.

[3]- American Psychiatric Association: Diagnostic and Statistical Manual of Mental Disorders,2000, Fourth Edition, Text Revision. Washington, DC, American Psychiatric Association, pp 345-427.

[4]- Seligman, M. E. P. (1975). Helplessness. San Francisco: Freeman Pub.

[5]- The World Health Organization. The world health report 2001 - Mental Health: New Understanding, New Hope.

[6]- Klerman G. L., Lavori P. W., Rice J., Reich T., Endicott J., Andreasen N. C., Keller M. B., \& Hirchfeld R. M. A. (1985). Birthcohort trends in rates of major depressive disorder among relatives of patients with affective disorder. Archives of General Psychiatry, 42, 689-693.

[7]- Murray C. L., \& Lopez A. D.1998. The global burden of disease: A comprehensive assessment of mortality and disability from disease, injuries and risk factors in 1990 and projected to 2020. Boston: Harvard University Press.

[8]- Safa, A. N. (2009). "Introduction to the burden of depression in Iran." Sepid weekly journal(150).

[9]- Beck A.T., Rush J.A., Shaw B.F., \& Emery G., 1979, Cognitive Therapy of Depression. New York: The Guilford Press.

[10]- Beck A.T., 1976, Cognitive Therapy and the Emotional Disorders. New York: Penguin Books.

[11]- Clark, D.A., Beck A.T., \& Alford B.A., 1999, Scientific Foundations of Cognitive Theory and Therapy. New York: John Wiley \& Sons.

[12]- Beck AT. 2002 Cognitive models of depression. Clinical advances in cognitive psychotherapy: Theory and application.14:29-61

[13]- Hammen C. and Goodman-Brown T. ,1990, Self-schemas and vulnerability to specific life stress in children at risk for depression. Cognitive Therapy and Research, 14 (2),215-227.

[14]- Miranda J.,1992, Dysfunctional thinking is activated by stressful life events. Cognitive Therapy and Research, 16 (4), $473-483$.

[15]- Seeds P.M. \& Dozois D.J.A. ,2010, Prospective evaluation of a cognitive vulnerability stress model for depression: The interaction of schema self-structures and negative life events. Journal of Clinical Psychology, 66 (12), 1307-1323.

[16]- Young J. E., Klosko J. S., \& Weishaar, M. E.,2003, Schema therapy: A practitioner's guide. New York: Guilford Press.

[17]- Stopa L. \& Waters A.,2005, The effect of mood on responses to the young schema questionnaire: short form. Psychology and Psychotherapy: Theory, Research, and Practice, 78, 45-57.

[18]- Wang C.E.A., Halvorsen M., Eisemann, M., and Waterloo K.,2010, Stability of dysfunctional attitudes and early maladaptive schemas: A 9-year follow up study of clinically depressed subjects. Journal of Behavior Therapy and Experimental Psychiatry, 
41, 389-396.

[19]- Halvorsen M., Wang C.E. Richter J., Myrland I., Pedersen S.K., Eisemann M., \& Waterloo K. ,2009, Early maladaptive schemas, temperament and character traits in clinically depressed and previously depressed subjects. Clinical Psychology and Psychotherapy, 16, 394-407.

[20]- Schmidt, N.B., Joiner, T.E., Young, J.E., and Telch, M.J. (1995). The schema questionnaire: investigation of psychometric properties and the hierarchical structure of a measure of maladaptive schemas. Cognitive Therapy and Research, 19 (3), 295 321.

[21]- Wang, C.E.A., Halvorsen, M., Eisemann, M., and Waterloo, K. (2010). Stability of dysfunctional attitudes and early maladaptive schemas: A 9-year follow up study of clinically depressed subjects. Journal of Behavior Therapy and Experimental Psychiatry, 41, 389-396.

[22]- Riso L.P., Maddux R.E., and Turini-Santorelli N.,2007, Early Maladaptive Schemas in Chronic Depression. In L. Riso, P. duToit, D. Stein, \& J. Young (Eds.), Cognitive Schemas \& Core Beliefs in Psychological Problems: A Scientist Practitioner Guide (pp. 4158). American Psychological Association.

[23]- Calvete, E., \& Cardeñoso, O. (2005). Gender differences in cognitive vulnerability to depression and behavior problems in adolescents. Journal of Abnormal Child Psychology, 33(2), 179-192. doi:10.1007/s10802-005-1826-y

[24]- Harris,Ashley E. \&Curtin,Lisa; Parental perception,early maladaptive schemas, and depressive symptoms in young adults, Cognitive therapy and research,Vol.26,No3,June 2002;PP405-416.

[25]- Young, J. \& Brown, G.,1994, Young Schemas Questionnaire - S1. New York, NY: Cognitive Therapy Center.

[26]- Thimm, J.C.,2010, Personality and early maladaptive schemas: A five-factor model perspective. Journal of Behavior Therapy and Experimental Psychiatry, 41, 373-380.

[27]- Petrocelli John V., Glaser Brian A., Calhoun Georgia B. \& Campbell Linda F., 2001, Early maladaptive schemas of personality disorder subtypes, Journal of Personality Disorders, 15(6), 546-559, The Guilford Press.

[28]- Halvorsen M., Wang C.E., Richter J., Myrland I., Pedersen S.K., Eisemann M., \& Waterloo, K. (2009). Early maladaptive schemas, temperament and character traits in clinically depressed and previously depressed subjects. Clinical Psychology and Psychotherapy, 16, 394-407.

[29]- Shah R, Waller G.,2000, Parental style and vulnerability to depression: the role of core beliefs. J Nerv Ment Dis.,188(1):19-25.

[30]- Colman, Lindsey K.,2010, "Maladaptive Schemas and Depression Severity: Support for Incremental Validity When Controlling for Cognitive Correlates of Depression.". Master's Thesis, University of Tennessee.

[31]- Beck, A., Steer, R. A., \& Brown, G.,1996, Beck Depression Inventory-II Manual. San Antonio,TX: The Psychological Corporation.

[32]- Renner Fritz, Lobbestael Jill , Peeters Frenk , Arntz Arnoud , Huibers Marcus ,2012," Early maladaptive schemas in depressed patients: Stability and relation with depressive symptoms over the course of treatment " Journal of Affective Disorders 136 (pp) 581-590.

[33]- Harris, A. E., \& Curtin, L.,2002, Parental perceptions, early maladaptive schemas, and depressive symptoms in young adults. Cognitive Therapy and Research, 26, 405-416.

[34]- Anmuth, Lindsay M., Haugh, Jim A.,2011, Early Maladaptive Schemas and Negative Life Events In the Prediction of Depression and Anxiety,A thesis for the degree of Master of Arts in Clinical Mental Health Counseling at Rowan University .

[35]- Beck A.T., Steer R.A. ,1993, Beck Anxiety Inventory Manual. San Antonio: Harcourt Brace and Company.

[36]- Dozois, D.J.A., Dobson, K.S., \& Ahnberg, J.L. ,1998, A psychometric evaluation of the Beck-Depression Inventory-II. Psychological Assessment, 10 (2), 83-89.

[37]- Dobson, K. S., Hopkins, J. A., Fata, L., Scherrer, M., \& Allan, L. C.,2010, The prevention of depression and anxiety in a sample of high-risk adolescents: A randomized controlled trial. Canadian Journal of School Psychology, 25(4) 291-310.

[38]- Dabson keith, P. M. "The Psychometric properties of the BD-II." Journal of Rehabilitation 8(2): 82.

[39]- Ladan Fathhi, B. B., Mohammad kazem Atefvahid, Keith stephan Dabson (2005). "The structure of naming of emotional states and cognitive processing of emotional information: A comparison of two conceptual frameworks." Journal of Psychiatry and Clinical Psychology 11(3): 312-326.

[40]- Stopa, L., Thorne, P., Waters, A., \& Preston, J.,2001, Are the short and long forms of the Young Schema-Questionnaire comparable and how well does each version predict psychopathology scores? Journal of Cognitive Psychotherapy, 15, $253-272$.

[41]- Waller, G., Meyer, C., \& Ohanian, V.,2001, Psychometric properties of the long and short versions of the Young SchemaQuestionnaire: Core beliefs among bulimic and comparison women. Cognitive Therapy and Research, 25, 137-147.

[42]- Welburn, Ken; Coristine, Marjorie; Dagg, Paul; Pontefract, Amanda; Jordan, Shelley // Cognitive Therapy \& Research;Aug2002, Vol. 26 Issue 4, p519 .

[43]- Ghiasi M.,2008,Validity and reliability of Young Schema Questionary (3rd. Short-form) in patient with psychological disorder and non-patient individuals in Tehran]. Thesis for Master degree. Iran, Isfahan: University of Isfahan.

[44]- Sareh Esfarjani Ezadian, A. p., Parvaneh Mohammadkhani, Behrooz Dolatshahi (2010). The role of early maladaptive schemas and apprehensiveness in explaining of depression symptoms University of Welfare and Rehabilitation Sciences, Tehran university of Medical sciences. Master.

[45]- Hankin B, Abramson L, Miller N, Haeffel G.,2004,Cognitive Vulnerability-Stress Theories of Depression: Examining Affective Specificity in the Prediction of Depression Versus Anxiety in Three Prospective Studies. Cognitive Therapy and Research,28(3):309-45.

[46]- Abela, J. R. Z., Auerbach, R. P., Yao, S., \& Zhu, X.,2008, Cognitive and interpersonal vulnerability to depression in adolescents in 
urban and rural China: A multi-wave longitudinal study. In Noortje Vriends and Andrew G. Ryder (Chairs), The cultural shaping of depression, social anxiety: Affective, cognitive, and interpersonal consequences. Paper presented at the 19th International Congress of the International Association for Cross-Cultural Psychology, Bremen, Germany.

[47]- Eberhart, N.K., Auerbach, R.P., Bigda-Peyton, J., \& Abela, J.R.Z. (2011). Maladaptive schemas and depression: Tests of stress generation and diathesis-stress models. Journal of Social and Clinical Psychology, 30, 75-104.

[48]- Oei, T. \& Baranoff, J. ,2007, Young Schema Questionnaire: Review of psychometric and measurement issues. Australian Journal of Psychology, 59, $78-86$. 